\title{
NOSSA UFRPE: Um protótipo inovador para a gestão da comunicação acadêmica
}

\author{
Marcelo Mendonça Teixeira, Joel Alves de Lima Júnior, Ivaldir Honório de Farias Júnior, Rafael Flanklin Fontes de \\ Oliveira, Micaías Paiva, Josival dos Santos Silva \\ Universidade Federal Rural de Pernambuco, Departamento de Química (Núcleo SEMENTE) / Departamento de Estatística e \\ Informática (DeInfo)
}

\begin{abstract}
Resumo
No presente trabalho abordamos o desenvolvimento de uma plataforma mobile vocacionada a gestão de problemas no campus universitário da Universidade Federal Rural de Pernambuco. Para tanto, optamos por um estudo qualitativo, de cariz empírico descritivo, suportado pela Metodologia de Desenvolvimento de um Protótipo. O estudo decorreu de Fevereiro de 2014 a Fevereiro de 2015. Palabras clave: Plataforma Mobile, IHC, Cidadania Digital, Campus Virtual.
\end{abstract}

\section{Introdução}

Novos modos de vida são permeados por uma cultura global que potencializa novas formas de sociabilidade no mundo contemporâneo através de tecnologias digitais, especialmente, pela tecnologia mobile, argumenta Teixeira (2013). Em outras palavras, trata-se de uma virtualização cultural da realidade humana, fruto da migração do espaço físico para o virtual (mediado pelas TIC), regido por códigos, signos e relações sociais próprias. Avante, surgem formas instantâneas de comunicação, interação e possibilidade de rápido acesso às informações, no qual não somos meros emissores, mas produtores, reprodutores, colaboradores e distribuidores daquelas. Com o avanço vertiginoso dos meios de comunicação, que agora denominam-se "net media", a inovação torna-se um bem maior para o desenvolvimento da comunicação em grupo, impulsionados por um movimento de contemporâneo de mobilidade (tables, smartphones, computadores portáteis, entre outros, são elementos importantes desta realidade). Movimento que se traduz na geração da conectividade e na geração do milênio. Neste momento de mudanças, que ora vivenciamos desde de meados do século XX, à Internet vem revolucionando a maneira que os indivíduos trocam informações, relacionam-se, aprendem, colaboram, trabalham, estudam, imensos numa teia de hipeligações e hipermidiaticações no universo virtual, "Linguagens líquidas na era da mobilidade" na perspectiva de (Santaella, 2007).

Acompanhando essa tendência, as plataformas tecnológicas vêm se diversificando cada vez mais, visando atender a demanda, atingindo a satisfação e comodidade de seus usuários, que migram da plataforma desktop para plataformas mobile, onde encontram maneira mais versátil de se estabelecer uma comunicação rápida e objetiva, visando o conforto e a praticidade de poder portar o aparelho em seu bolso, ideario da portabilidade, segundo (Teixeira, 2013). Nesta conjuntura, através das novas tecnologias de informação e comunicação, surge uma nova metodologia de tratamento dos problemas encontrados no seio das instituições de ensino, em favor de uma gestão administrativa e educacional eficiente, bem como em benefício do processo de ensino e aprendizagem. É nesse sentido que abordamos, neste trabalho, uma plataforma mobile acadêmica de monitoramento de problemas na instituição de ensino, ao mesmo tempo, um recurso tecnológico de apoio didático para educadores. Da teoria à prática, evidenciamos o protótipo desenvolvido para a Universidade Federal Rural de Pernambuco.

\section{Metodologia de Investigação}

O trabalho em voga é de cariz qualitativo e empírico descritivo, e baseia-se na metodologia de desenvolvimento de um protótipo, apesar da reduzida literatura sobre o tema, se limitando as obras de Akker (1999) e Maren (1996), mas plenamente coerente com a nossa pesquisa. Ao nível dos métodos e técnicas, a metodologia de desenvolvimento recorre maioritariamente ao método do estudo de caso, focalizado na concepção, observação, desenvolvimento e apresentação da ferramenta ou objeto desenvolvido, de acordo com Van Der Akker (1999). É nesse sentido que o presente estudo foi realizado de Janeiro de 2014 a Janeiro de 2015 no campus da Universidade Federal Rural de Pernambuco, e o protótipo desenvolvido no Núcleo SEMENTE (Sistemas para elaboração de Materiais Educacionais com o uso de Novas Tecnologias), vinculado ao Departamento de Química da UFRPE. Trata-se de uma proposta inovadora para instituições ensino no Brasil.

\section{Cidadania Digital}

As tecnologias, os equipamentos e as linguagens que nelas circulam, propiciadoras de uma nova lógica cultural, permitem a escolha e o consumo mais personalizado e individualizado das mensagens, em oposição ao consumo massivo, conta (Santaella, 2007). São justamente esses processos que constituem a cultura das mídias. "Portanto, essa cultura constitui num período de passagem, de transição, funcionando como uma ponte entre a cultura de massas e a cibercultura" (ibidem, p.125). Nicolau (2010), recorda que são concepções corroboradas por Henry Jenkins a partir de sua ideia da 
"Cultura da Convergência", fixado no fluxo de conteúdos através de múltiplos suportes midiáticos em plena cooperação, associado ao comportamento migratório dos públicos dos meios de comunicação, capazes de irem a quase qualquer parte em busca das informações desejadas. Vivenciando uma sociedade de consumo, legitimamos a Cultura da Convergência pelo senso comum, na procura incessante por individualidade, autonomia, reconhecimento social, nacionalidade, sexualidade e interação social, antes cerceada pela despersonalização e unidimensionalidade dos tradicionais meios de comunicação.

Uma vez imersos na cultura de massas, cultura midiática, cultura da convergência, cultura da mobilidade e na cibercultura, os seres humanos precisam aprender a dicernir e a criticar as informações repassadas pelos novos e antigos meios de comunicação, evitando assim à manipulação sociocultural. Numa ótica mais ambrangente, discutida por Macquail no livro "Media performance: mass communication and the public interest", o público é incentivado a ser mais consciente e seletista frente as empresas de comunicação relacionadas com a produção midiática em massa, pois, ao mesmo tempo que representam a liberdade de opinião, aliciam as massas em benefício próprio.

Seguindo a esta retórica, as tendências evolutivas dos meios de comunicação que ocorrem a nível mundial, trazem consigo novas questões para profissionais de ensino e gestores escolares encontrarem resposta: compreender as novas interpretações da tecnologia e da cultura, decorrentes da intersecção entre a tecnologia, a comunicação e a educação, e entender os novos desafios estratégicos que se colocam as mídias tradicionais subjacente à referida diversificação cultural, conduzindo a uma coabitação de gêneros e suportes no universo virtual, acredita Soares (2005), promovendo e popularizando suas aplicabilidades educativas dentro e fora das salas de aula. Igualmente, conhecer os fatores que afetam o bem estar dos discentes no seio da instituição de ensino, influencia de forma direta e indireta a qualidade do processo educativo. Valorizando tais princípios, a UFRPE acreditou na proposta de desenvolvimento de um protótipo mobile vocacionado a ouvidoria da instituição de ensino, denominado Nossa UFRPE, servindo, idem, a propósitos educacionais.

Em termos de participação cidadã através das interfaces "mobile", o processo de inclusão digital não se faz presente no Brasil, verifica Teixeira (2013), se considerarmos, inclusive, o contingente populacional com acesso a rede e outros tantos que a utilizam para exclusivos fins de entretenimento e interação comunicacional com seus pares, espelho da falta de conhecimento e conciência em fazer valer seus direitos. É por isso que Mike Rible citado em Teixeira e Lima Júnior (2013) defendem que para sermos cidadãos produtivos precisamos estar comprometidos com à igualdade de acesso digital. Ou seja, a participação igualitária de todos cidadãos é de suma importância no processo de fiscalização, sugestão e avaliação dos problemas encontrados na instituição de ensino, da infraestrutura ao ambiente educacional nas salas de aula. Sob esse prisma, o universo virtual tem possibilitando ao cidadão à participação direta, flexível e efetiva em termos de interação comunicacional junto ao poder público, sinônimo da "cidadania digital", como se destaca na figura a seguir, assente na proposta de [Ibidem]:

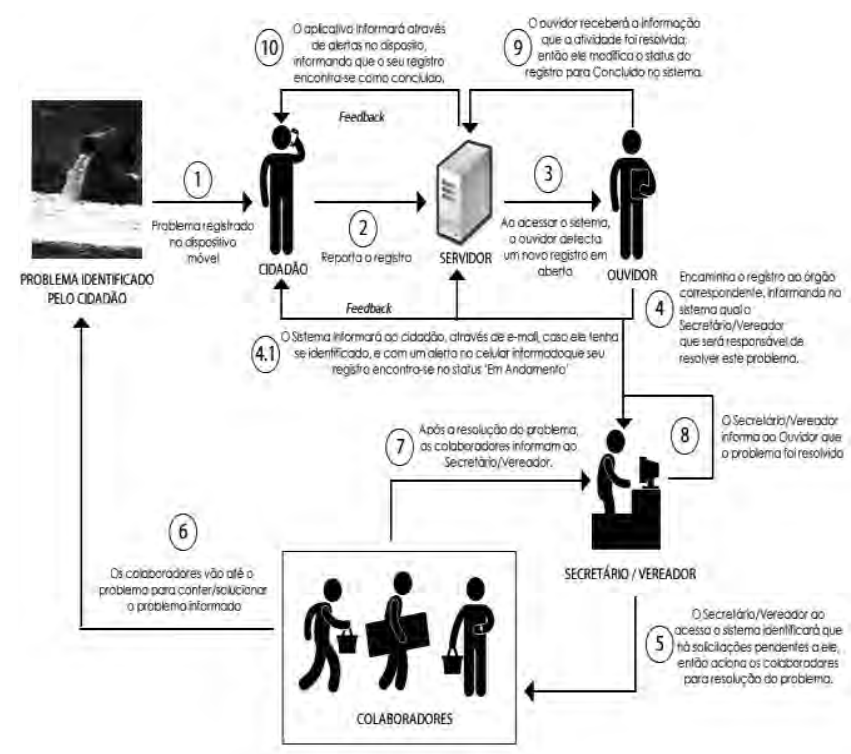

Figura 1. Proposta de Cidadania Digital

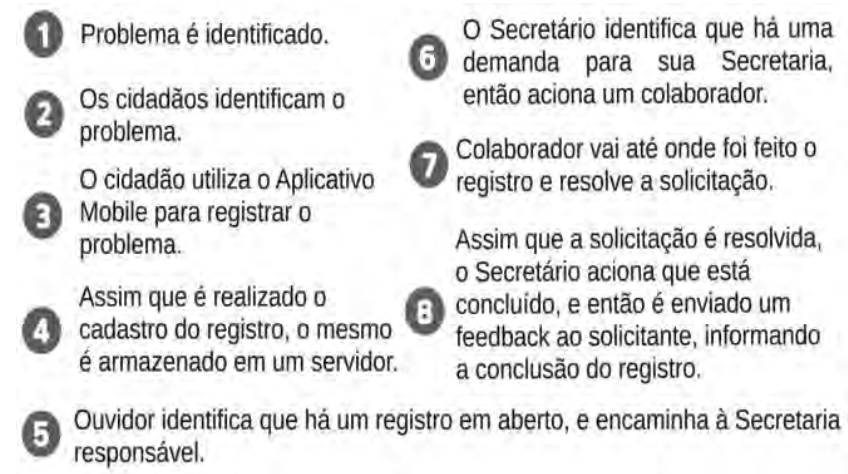

A sociedade e as autoridades políticas normalmente se deparam com diversos problemas no ambiente público, desde buracos nas estradas, falta de iluminação pública, ruas depredadas, estradas sem sinalização, lixo acumulado, esgoto a céu aberto, acessibilidade, entre tantos outros. A partir deste cenário, constatamos demandas semelhantes nos campus das instituições de ensino.

\section{Nossa UFRPE}

O software Nossa UFRPE trata-se de uma nlataforma móvel aue contemnla o nrocesso de gestão de nroblemas existentes dentro do camnus e nas áreas circundantes da instituicão de ensino identificados nela comunidade acadêmica. tornando-se um eficiente recurso nara auxiliar nas tomadas de decisão nelo gestor educacional. seia este ouvidor. nró-reitor. vice-reitor e/ou reitor da universidade. É seguindo tal nremissa aue enfatizamos uma alternativa viável em termos de servico núblico nara a nonulacão estudantil. elevando a aualidade de ensino soh diversos asnectos. Por esse motivn. as contrihuicões do nosso protótipo versam tanto sobre a concepção e 
disponibilização do software, quanto ao registro das informações de interesse público (incluindo recursos de acessibilidade), ficando, aqui disposta, uma proposta concreta para a implementação em qualquer contexto social, além do acadêmico.

Em âmbito geral, em termos de gestão acadêmica de instituições de ensino públicas e privadas no Estado de Pernambuco, obervamos: a) ausência de instrumentos de acompanhamento para a solução dos problemas e de feedback para a sociedade; b) sistemas de informação fragmentados e não padronizados; c) dificuldade de auxiliar o diagnóstico dos problemas; c) ausência de planos de ação incorporados para auxiliar a solução da solicitação apresentada, entre outros. Daí, fizemos as seguintes perguntas a gestores da UFRPE (Campus Sede em Recife):

1. Atualmente, é possível identificar os problemas de infraestrutura e serviços da instituição de ensino de forma contínua através da comunidade acadêmica?

2. Se sabe informar e detalhar quando um problema foi identificado, o tempo para a sua solução e o retorno informativo ao denunciante?

3. Se faz um mapa dos problemas por setor, centro ou departamento, destacando as áreas prioritárias para a ação administrativa?

4. Quando ele tomou conhecimento do problema?

5. Qual a medida que foi adotada?

6. O problema foi resolvido?

7. Paralisou em algum local? Porque? Por quanto tempo?

8. Após a solução, alguém checou se, efetivamente, o problema foi corrigido?

9. O usuário recebeu feedback da solução adotada?

10. Qual foi a solução adotada para um problema reincidente ou Existe alguma biblioteca de melhores práticas para solução de problemas?

Todas as respostam convergiam com à evidente necessidade de um sistema que viesse a padronizar a solução para estas e outras questões de maneira efetiva e em custo espaço de tempo. Comumente, tais demandas são recebidas ou encaminhadas por meio da ouvidoria institucional.

Em relação direta ao processo de ensino e aprendizagem, a falta de livros na biblioteca, lâmpadas queimadas, falta de material didático (giz, projector, apagador de quadro, etc.), falta de professor para uma determinada disciplina ou mesmo, a alocação de um professor que não é da área do conhecimento específica, são alguns dos problemas mais comuns encontrados em instituições de ensino. Surge, então, um modelo tecnológico para o monitoramento dos problemas comentados em epígrafe. Mas como dar-se-à o processo do registro até a resposta final para o demandante?
Vejamos as etapas a seguir:

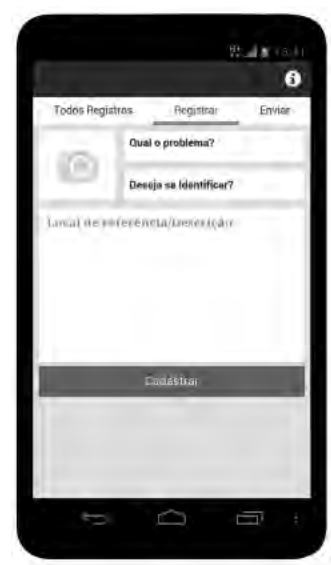

Figura 2. Registrando o problema

O usuário realiza o registro do problema por meio do smartphone, tablet, passando a receber o feedback imediato da tramitação da demanda.

Após realizar o envio dos dados cadastrados, o usuário será submetido à uma tela onde ele visualizará todos os registros que foram enviados por seu dispositivo móvel, seguindo de informações da categoria escolhida, um resumo de sua descrição e o status de cada um dos seus registros (sinônimo de notificações).

Os registros passaram por três tipos de status, são eles: Novo, Em Andamento e Concluído, tais status expressam em que condições atuais encontram-se os registros e suas representações visuais são a partir de cores. Mas como estes registros vão auxiliar no processo de resolução de problemas? Os registros que serão reportados pela sociedade, passaram por uma espécie de análise e a partir disto será possível visualizar a situação de diversas regiões do município em uma visão macro, identificando quais os problemas que vem dificultando a vida de muitos moradores daquela região. O mapa que será utilizado para a visualização macro será o Google Maps (ao qual serão mostrados posteriormente). A partir destes dados, o ouvidor juntamente com autoridades políticas, que são representantes do povo, irão tomar medidas para conter/solucionar o problema de maneira rápida e efetiva, utilizando os dados da aplicação como apoio para reconhecimento da localidade destes problemas.

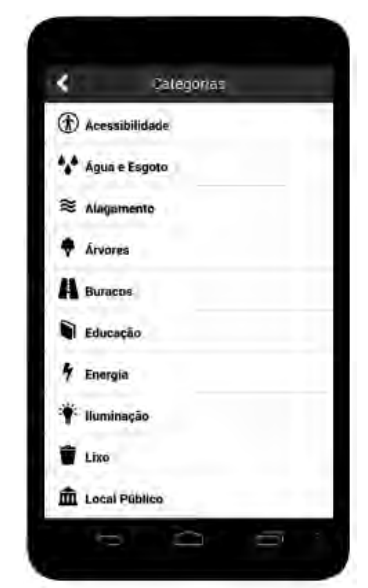

Figura 3. Classificando o problema 
A sistema permite a utilização de categorias que facilitam a seleção de problemas que se relacionam. A classificação permitirá a elaboração de estatísticas dos principais problemas, possibilitando ao gestor a elaboração de planos de ação para um grupo específico de problemas de determinada localidade.

Funcionando Off Line - o sistema funciona mesmo que não haja conexão com à Internet. Será possível o registro de todos os problemas que forem identificados e quando estiver conectado, poderá transmitir todos os registros.

No ato do registro, o aplicativo irá capturar a latitude e longitude exata da localização do problema através de recursos de GPS do próprio dispositivo móvel, e assim realizar o cadastro da sua marcação utilizando serviços do banco de dados local do próprio aparelho para o armazenamento. Um dos grandes problemas para aplicativos deste porte é a conexão com a Internet, pois no Brasil, as redes de telefonia móvel 3G ainda não alcançaram as expectativas esperadas no quesito de conectividade e as $4 \mathrm{G}$ ainda estão no processo de adaptação, então pensando nesta dificuldade, o sistema irá realizar os cadastros dos registros off-line, ativando apenas os serviços de GPS, com esta premissa o usuário poderá então usurfruir do aplicativo sem necessitar estar conectado à uma rede no ato do registro, facilitando assim a efetuação dos registros em localidades que ainda não possuem o sinal de Internet, como por exemplo áreas rurais.

Mas como funciona o envio destes registros? Assim que o usuário se conectar a uma rede WIFI, $3 G$ ou $4 G$, o aplicativo identificará que há conectividade, a partir disto, informará que existe registros que foram realizados no modo off-line e que precisam ser enviados, pois para que possam tornar-se válidos é necessário que sejam submetidos ao servidor, então o aplitavo mostrará uma tela informando a quantidade de registros que foram realizados e um botão "Enviar Registros". Assim que o usuário pressionar o botão de "Enviar Registros", o aplicativo irá submeter todos os dados que forma cadastrados off-line ao servidor, vejamos:

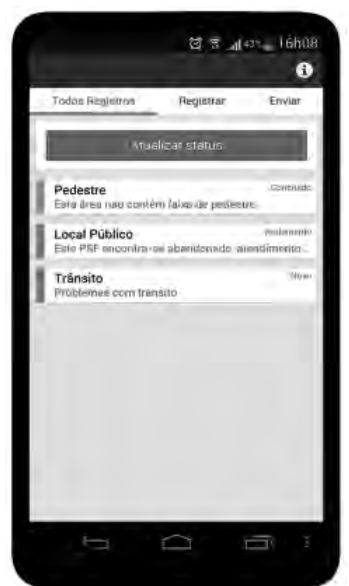

Figura 4. Acompanhando os registros

O monitoramento do status da solução do problema é possível pelo próprio aparelho que o registrou. O usuário acompanhará facilmente a evolução da solução do problema por meio de um sistema de cores, que será atualizado automaticamente, permitindo ao usuário verificar o que é novo, o que está em andamento e o que já foi concluído. A partir destes dados, o ouvidor ou gestor educacional (pró-reitor, vice-reitor, reitor), irão tomar medidas para conter/solucionar o problema de maneira rápida e efetiva, utilizando os dados da aplicação como apoio para reconhecimento da localidade daquele. Na prática, observamos as telas no sistema:

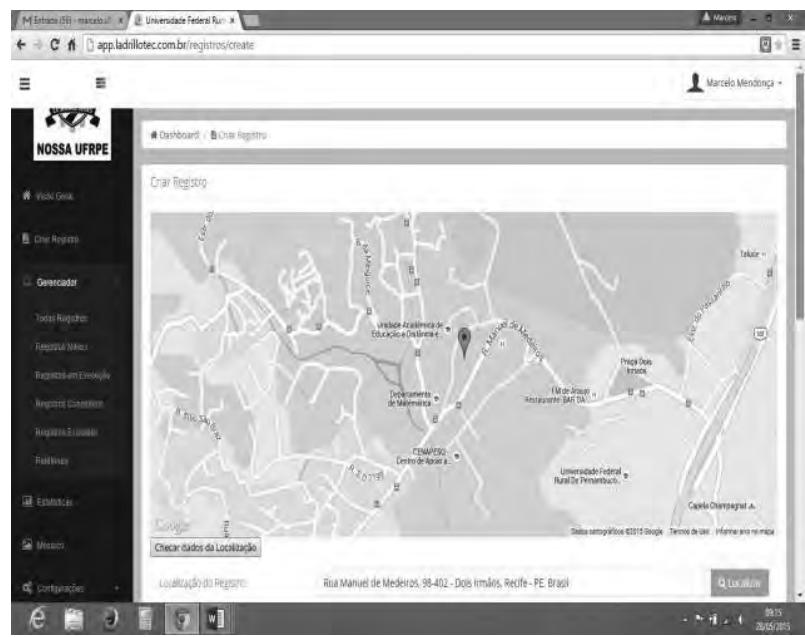

Figura 5. Mapa de registro geolocalizados

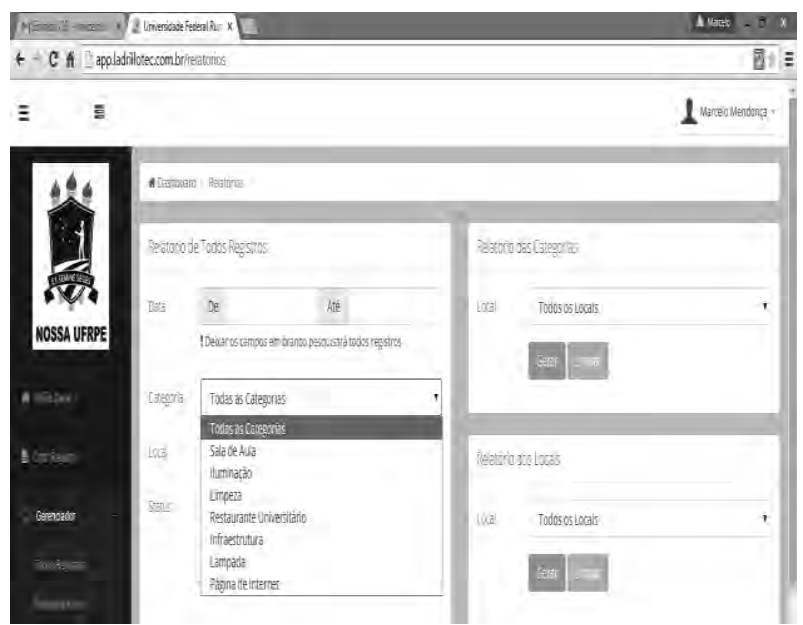

Figura 6. Categorias dos problemas

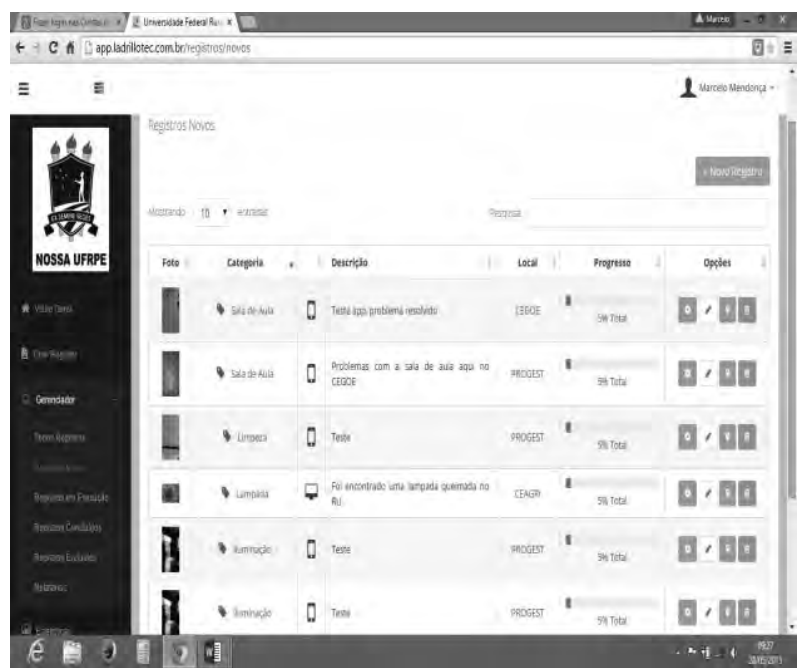

Figura 7. Status de resolução dos problemas 


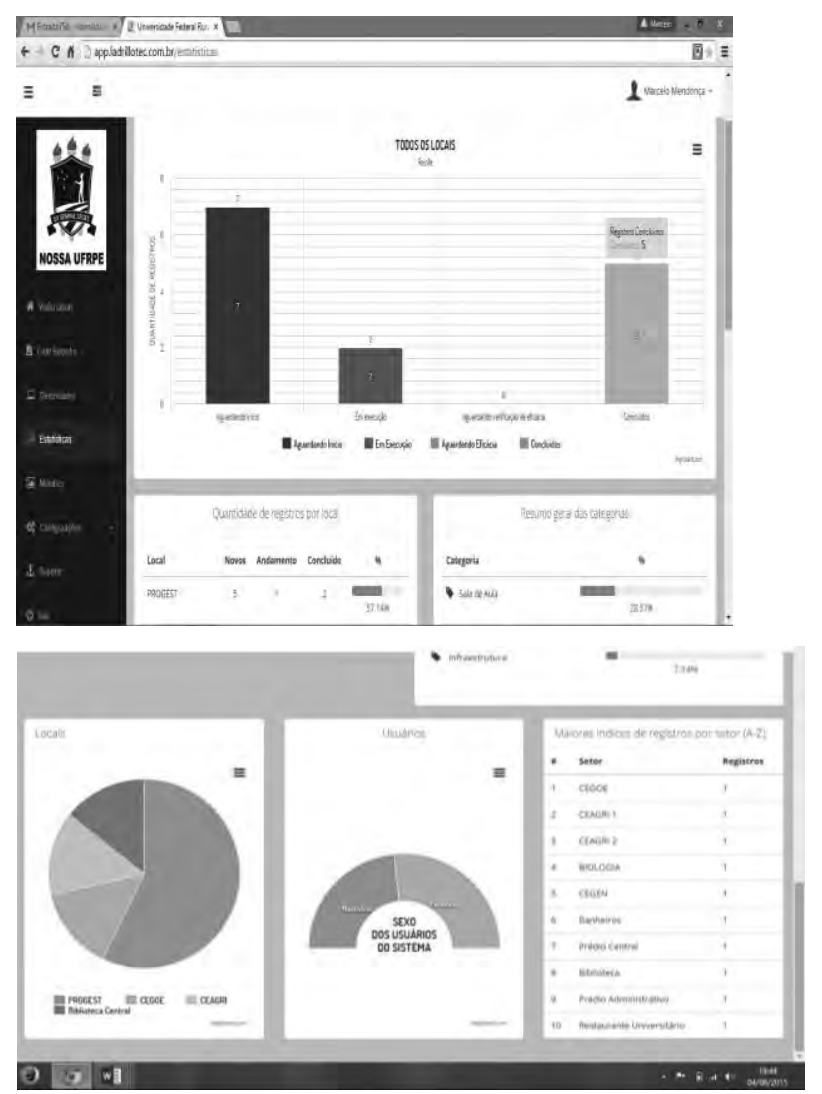

Figura 8. Relatórios estatísticos

Nas figuras 5, 6, 7, 8, o gestor determina às prioridades de atendimento das demandas solicitadas por área, por setor, por departamento, por centro de ensino ou pela urgência em resolver tal problema. É possível visualizar os dados que foram submetidos pelo discente, docente, técnico administrativo e demais membros da comunidade acadêmica local, gerar gráficos estatísticos e o status para a resolução dos problemas registrados.

Após o registro ser resolvido pelo órgão responsável, o gestor se encarregará de modificar o status da solicitação para "Concluído". Assim, ele poderá relatar de maneira simples e objetiva quais foram os procedimentos que precisaram ser tomados para a resolução do problema.

Por fim, através de mecanismos de e-mail e alerta no próprio dispositivo móvel, o cidadão receberá diversas notificações de como está o andamento da sua solicitação, qual o representante político que está a frente deste problema, o protocolo de sua solicitação, dentre outras informações no que diz respeito a seu registro. Este feedback para a sociedade é um fator essencial neste processo, pois a informação em caráter de retorno de um chamado é uma garantia do comprometimento e da responsabilidade social da gestão pública para com a sociedade.

O processo de feedback é de suma importância para sociedade e para o processo comunicativo, pois com a evolução da Web 2.0, vários mecanismos se adequaram a este novo modelo de comunicação, que intervém modificando estado passivo-receptivo para um estado ativo-comunicativo, estabelecendo assim a comunicação de ambas as partes. Quanto ao mecanismo do feedback, além do envio da mensagem original, a informação retorna descodificada pelo receptor à fonte ou emissor, para que este possa conhecer o resultado de sua mensagem.

\section{Conclusão}

A emergência de novas formas de sociabilidade no mundo contemporâneo fomentou outros rumos ao desenvolvimento tecnológico, transformando e criando relações inusitadas do homem com as tecnologias de comunicação e informação. Seguindo essa premissa, o software Nossa UFRPE condiciona uma comunicação efetiva entre comunidade acadêmica e os gestores educacionais, muito além de um simples sistema de ouvidoria digital. Através da pesquisa científica e do desenvolvimento do protótipo em curso, observamos que os registros de diferentes tipos de problemas encontrados em uma instituição de ensino superior podem ser geridos a partir de plataformas tecnológicas móveis, auxiliando precisamente no processo de identificação dos problemas, reduzindo o tempo para resolução daqueles, uma vez que será encaminhado para o setor específico responsável, minimizando os gastos financeiros com a alocação de materais e funcionários terceirizados ou efetivos desnecessários para algumas situações.

Em suma, a proposta em curso, inédita na América Latina e elogiada durante o III Fórum de Ouvidores das Instituições de Ensino Superior de Pernambuco, realizado na UFRPE em Julho e Agosto de 2014, reconhece a importância da opinião pública e esta, em simetria, sente-se representada e satisfeita em ser atendida suas demandas, e quando não, ter uma posição sobre o motivo que impossibilitou sua resolução, com previsão de tempo futuro para a resposta. Ou seja, melhora a comunicação, consolida a participação democrática popular, satifaz a opinião pública, dar suporte a tomada de decisão para os gestores, reduz o tempo e os recursos financeiros demandados e contribui diretamente na qualidade do processo educativo.

\section{Referências}

Nicolau, M. (2010). A busca por uma web semântica cognitiva. In Revista Temática, ano 7, nº 7, p. 1-15.

Santaella, L. (2007). Linguagens líquidas na era da mobilidade. São Paulo: Paulus.

Soares, T. (2005). Os meios de comunicação social na Internet: contributos para a análise sociológica dos cibermedia. http://www.bocc.ubi.pt/pag/soares-tania-meios-comunicaca o-social-internet.pdf. Acesso em 03 de Novembro de 2014.

Teixeira, M. M. (2013). Da educação a distância às plataformas de aprendizagem: sistemas alternativos de educação mediada. Munique: Grin Verlag.

Teixeira, M. M. \& Lima Júnior, J. A (2013). Cidadania digital: uma proposta de dispositivo móvel para o monitoramento das cidades. Revista Temática, ano IX, n. 12, p.1-22.

Van Den Akker, J. M. (1999). Principles and methods of development research. Netherlands: Kluwer Academic Publish.

Van Den Akker, J. M. (1996). Méthodes de recherche pour l'éducation. Collection méthodes en sciences humaines. Bruxelles: DeBoeck Université. 